\title{
Characteristics of Flavobacterium branchiophilum Isolated from Rainbow Trout in Korea
}

\author{
Young-Min Ko and Gang-Joon Heo \\ Laboratory of Aquatic Animal Diseases, College of Veterinary Medicine, Chungbuk National University, \\ Cheongju 360-763, Korea
}

(Received October 29, 1996)

\begin{abstract}
Outbreaks of bacterial gill disease (BGD) occurred among cultured rainbow trout (Oncorhynchus mykiss) in Chungbuk province of Korea. Gram-negative, filamentous and yellow-pigmented bacteria were isolated from the diseased fish. The morphological, physiological, biochemical, and antigenic properties of the Korean isolates were consisted with those of Flavobacterium branchiophilum (ATCC $35035^{\mathrm{T}}$ and ATCC 35036) isolated from salmonid fish in Japan and Oregon, USA. It was concluded that the Korean isolates were identified as $F$. branchiophilum.
\end{abstract}

Key words: Korea, BGD, Flavobacterium branchiophilum, rainbow trout

Bacterial gill disease (BGD) is an economically significant gill disease of cultured teleost in many countries (Daoust and Ferguson, 1983; Farkas, 1985; Wakabayashi et al., 1980, 1989; Bullock, 1990). The disease caused physical irritation to the fish and impaired the respiratory function of the gills by large numbers of filamentous, Gram-negative bacteria associated with the surface of the gill epithelium.

Traditionally most yellow-pigmented bacteria (YPB) recovered from fish with BGD have been classified as "myxobacteria" and usually identified as members of the genus Flexibacter or Cytophaga. One specific genus however, did not appear to be common among all BGD outbreaks, and axenic cultures were seldom recovered from natural outbreaks (Rucker et al., 1952; Anderson and Conroy, 1969; Ostland et al., 1990). Filamentous YPB from some salmonid fish with BGD in Japan, the northwestern USA (Oregon), and Hungary were classified as Flavobacterium branchiophilum (Wakabayashi et al., 1980, 189; Farkas, 1985; von Graevenitz, 1990).

A filamentous, gram-negative YPB resembling $F$. branchiophilum was recently isolated from rainbow trout (Oncorhynchus mykiss) affected with BGD in Korea. The bacteria appeared on the gills of young rainbow trout within 18-24h after fish were exposed to bacterial suspensions in aquaria. Based on the physiological, biochemical, and antigenic characteristics, three isolates were identified as $F$. branchiophilum.

\section{Materials and Methods}

\section{Bacterial strains}

During outbreaks of BGD, three strains of filamentous, gram-negative YPB were isolated from commercially reared rainbow trout in Chungbuk province of Korea (Table 1). These YPB were isolated by swabbing several gill arches and streaking the sample directly onto cytophage medium containing $1.5 \%$ agar $(1.5 \% \mathrm{CA}$; Anacker and Ordal, 1959). The isolates were maintained and subcultured on $1.5 \% \mathrm{CA}$ at $18^{\circ} \mathrm{C}$ or stored in cytophaga broth (CB; pH7.0) containing $15 \%$ glycerol at $-70^{\circ} \mathrm{C}$ until required.

Two reference strains (Table 1) of $F$. branchiophilum were used for comparative purposes. These were purchased from the American Type Culture Collection (ATCC, Rockwille, Maryland).

\section{Morphology and growth studies}

The following criteria of Holmes et al. (1984) were used for identification of the YPB from affected gills. Additional criteria and methods of Wakabayashi et al. $(1980,1989)$ were used to compare the biochemical characteristics of the Korean isolates with $F$. branchiophilum isolated in Japan and Oregon. Cells used for the study were grown in $\mathrm{CB}$ for $48 \mathrm{~h}$ at $18^{\circ} \mathrm{C}$ on a rotary shaker. Unless otherwise indicated, incubations were standardized to 7 days at $18^{\circ} \mathrm{C}$. Standard microbiological methods were used to interpret tests 
Table 1. Strains of Flavobacterium branchiophilum used in this study

\begin{tabular}{lcc}
\hline \hline Isolate & Year of isolation & \multicolumn{1}{c}{ Host species } \\
\hline \multicolumn{2}{c}{ Korean isolates } \\
CB1 & 1996 & Rainbow trout (Oncorhynchus mykiss) \\
CB2 & 1996 & Rainbow trout \\
CB3 & 1996 & Rainbow trout \\
& \multicolumn{2}{c}{ Reference strains } \\
ATCC 35035 & 1977 & Cherry salmon (O. masou) (Japan) \\
ATCC 35036 & 1978 & Chinook salmon $($ O. tshawytscha) (Oregon) \\
\hline
\end{tabular}

\section{(MacFaddin, 1980).}

Cell morphology was determined by light microscopy of gram-stained smears, or electron microscopy. Colonial spreading was determined by point inoculation on a freshly poured cytophaga agar plate containing $0.9 \%$ agar $(0.9 \% \mathrm{CA})$ and incubation in a humid chamber.

Motility was determined by phase-contrast microscopy of a hanging drop prepared from a CA culture. The absence of flagella was confirmed by incubating one drop of a $48 \mathrm{~h} \mathrm{CB}$ culture on copper grid coated with collodion and carbon, staining it with $2 \%$ phosphotungstic acid, and examining the grid on a transmission electron microscope (TEM). The method of Perry was also used to test for gliding movement (Perry, 1973).

Growth temperature was determined by streaking bacterial samples onto $1.5 \% \mathrm{CA}$ and incubating the cultures aerobically at $5,10,18,25,30$, and $37^{\circ} \mathrm{C}$ for 1.4 weeks, depending on the incubation temperature. Anaerobic growth was tested by steel wool method in anaerobic jar (Mitsuoka et al., 1969). The tolerance to $\mathrm{NaCl}$ was determined by inoculating $\mathrm{CB}$ containing 0 , $0.025,0.05,0.075,0.1$, or $0.2 \% \mathrm{NaCl}$ and recording the amount of growth for more than 2 weeks. Growth on tryptic soy agar (TSA), MacConkey's agar (MCA), and nutrient agar (NA) was checked by streaking samples from $1.5 \%$ CA cultures.

\section{Biochemical characterization}

Standard methods (MacFaddin, 1980) were employed by using CA or CB cultures for biochemical characterization of the strains unless otherwise stated.

To examine aerobic carbohydrate utilization, the low peptone medium described by Wakabayashi et al. (1980) was used. The inoculated media were incubated on a rotary shaker (200rpm) and examined for acidification daily for 7 days. The following carbohydrate were tested: dextrose, frutose, lactose, sucrose, maltose, trehalose, cellobiose, arabinose, xylose, rhamnose, raffinose, mannose, salicin, and galactose.

Penicillin $\mathrm{G}$ sensitivity was determined by placing an single antibiotic disk (10 units, BBL SensiDisk susceptibility test disks; Becton Dickinson) on a $1.5 \%$ CA plate seeded with $100 \mu l$ of CB culture. The organism was considered penicillin sensitive if the diameter of inhibition zone was larger than $20 \mathrm{~mm}$ after 7 days of incubation.

The presence of cell-wall-associated flexirubin-like pigments was determined by flooding $1.5 \% \mathrm{CA}$ colonies with $20 \% \mathrm{KOH}(\mathrm{w} / \mathrm{v})$.

Hydrolysis of gelatin was detected by mercuric chloride procedure of Frazier (MacFaddin, 1980). Cellulose degradation was determined by adding a sterile strip of Whatman No.1 filter paper to a freshly seeded CB culture and allowing static incubation for 30 days.

\section{DNA base composition}

DNA base composition was determined by reversedphase high-performance liquid chromatography (HPLC). Genomic DNA was resuspended in distilled water after isolated from a $5 \mu l$ culture. The isolated DNA was hydrolysed into nucleosides with nuclease P1(Sigma) and bacterial alkaline phosphatase (Sigma). The molar percentage of guanine plus cytosine in the DNA (mol\% $\mathrm{G}+\mathrm{C}$ ) was calculated using reversed-phase HPLC (Jin and Komagata, 1984). ATCC $35035^{\mathrm{T}}$ and ATCC 35036 strains served as controls.

\section{Antigenic characterization}

The antigenic relationships among the Korean isolates and the BGD reference strains were examined by microtiter agglutination and double immunodiffusion.

Bacterial antigen: Whole-cell bacterial antigens for immunization were prepared as follows. Several colonies from a $1.5 \% \mathrm{CA}$ culture of each strain were inoculated into $1 l$ of CB in a $2 l$ flask and grown for $48 \mathrm{~h}$ (approximated $10^{7} \mathrm{cfu} / \mathrm{m} l$ ). Cells were killed by adding 
$100 \mathrm{~m} l$ of $0.5 \%(\mathrm{v} / \mathrm{v})$ formalinized PBS (f-PBS) and incubating overnight at $10^{\circ} \mathrm{C}$. The following day cells were harvested by centrifugation, resuspended in $25 \mathrm{ml}$ of f-PBS and stored at $4^{\circ} \mathrm{C}$ until required.

Hear-stable antigens were prepared from whole-cell antigens of each strain using methods similar to Wakabayashi et al. (1989). A $1 l$ CB culture was steamed for $30 \mathrm{~min}$, cooled for $15 \mathrm{~min}$ at $-70^{\circ} \mathrm{C}$, and centrifuged at $10,000 \times \mathrm{g}$ for $20 \mathrm{~min}$ at $5^{\circ} \mathrm{C}$. The pellet was resuspended in $25 \mathrm{~m} l$ of f-PBS and stored at $4^{\circ} \mathrm{C}$ until used. For agglutination tests, both whole cell and heat-stable antigens were washed twice in PBS and adjusted to an optical density of $1.0(550 \mathrm{~nm})$ with PBS prior to use.

Preparation of antiserum: One milliliter of formalinkilled bacterial cells in Freund's complete adjuvant was injected subcutaneously into the backs of white rabbits weighing approximately $2.5 \mathrm{~kg}$. After 2 weeks, a booster injection with Freund's incomplete adjuvant was given subcutaneously. The blood was collected 2 weeks after the second injection, inactivated at $56^{\circ} \mathrm{C}$ for $30 \mathrm{~min}$, and frozen at $-20^{\circ} \mathrm{C}$.

Agglutination test: The microtiter technique for agglutination test was used to examine the serological relationship among the strains.

Immunodiffusion test: For immunodiffusion tests, souble antigens were prepared by sonication (three times at $200 \mathrm{~W}$ for $5 \mathrm{~min})$ or heart-treatment $\left(121^{\circ} \mathrm{C}, 30 \mathrm{~min}\right)$ of f-PBS-killed bacteria.

The double immunodiffusion test was performed with the use of $1 \%$ agarose gel. Soluble antigens were added to the duplicate outer peripheral wells and the undiluted antiserum was added to the central well (approximate volume per well, $25 \mu l$ ). Gels were incubated for 2 days at $20^{\circ} \mathrm{C}$ before examination.

\section{Results}

Morphologic, phenotypic, and genomic characterisitcs

The cells of all the present isolates as well as reference strains were gram-negative slender rods measuring 0.5 by 8 to $15 \mu \mathrm{m}$, and they usually occurred in chains of two or three cells in CB (Fig. 1). They were nonmotile and showed neither gliding movement nor swarming growth on agar media.

Growth on CA was usually slow, with colonies appearing only after 2 to 5 days of incubation at $18^{\circ} \mathrm{C}$. The colonies were light yellow, round transparent, smooth, and about 0.5 to $1 \mathrm{~mm}$ in diameter after incubation for 5 days. All strains grew well at 10

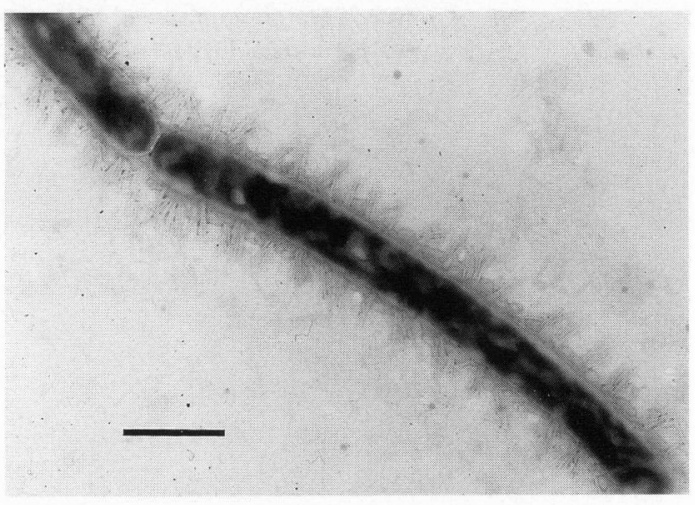

Fig. 1. Election micrograph of Korean isolate CB1 demonstrating thin, fimbria-like appendages extending from bacterial surface. Bar $=1 \mu \mathrm{m}$.

through $30^{\circ} \mathrm{C}$, and at 0 through $0.1 \% \mathrm{NaCl}$. None of the strains grew anaerobically, at $37^{\circ} \mathrm{C}$, nor at $0.2 \% \mathrm{NaCl}$.

All strains used were sensitive to penicillin $\mathrm{G}$, and zones of inhibition ranged from 55 to $64 \mathrm{~mm}$ (Table 2). Cytochrome-c oxidase and catalase were positive in all strains. None of the strains displayed typical flagellar or glinding motility, but TEM studies demonstrated fimbria-like structures originating from their cell surface (Fig. 1). The agar colony pigments were not of the flexirubin type. All strains failed to produce indole and $\mathrm{H}_{2} \mathrm{~S}$, reduce nitrate or hydrolyze esculin.

No strains gave any reaction anaerobically in the $\mathrm{OF}$ medium, but produced acid aerobically and therefore considered to be an oxidative type. All of the strains tested hydrolyzed gelatin, starch, and casein, but not cellulose.

The values for $\mathrm{G}+\mathrm{C}$ content of all Korean isolates were similar to those of $F$. branchiophilum reference strains (range $30-31 \mathrm{~mol} \%$ ) (Table 3).

The carbohydrate utilization profiles were variable. All strains tested produced a strong acid reaction from dextrose and sucrose after 3 days of incubation (Table 4).

\section{Antigenic characterisitics}

Microtiter agglutination test: Agglutinin titers of antisera for homologous formalin-killed cells ranged from 1024 to 4096 and those for heat-killed cells ranged from 64 to 256 (Table 5). The agglutinin titers of antisera for heterologous formalin-killed cells ranged from 128 to 1024 and those for heat-killed cells from 32 to 128 . The Korean isolates shared varying degrees of 
Table 2. Morphological and physiological characteristics of Korean isolates and $F$. branchiophilum reference stranis

\begin{tabular}{lccccc}
\hline \hline Characteristic & CB1 & CB2 & CB3 & ATCC35035 & ATCC35036 \\
\hline Gram reaction & - & - & - & - & - \\
Motility & - & - & - & - & - \\
Gliding movement & - & - & - & - & - \\
Swarming & - & - & - & - & - \\
Anaerobic growth & - & - & - & - & - \\
Growth at 30 $\mathrm{C}$ & + & + & + & + & + \\
Growth in $0.1 \% \mathrm{NaCl}$ & + & + & + & + & + \\
Growth on & & & & & \\
TSA & - & - & - & - & - \\
MCA & - & - & - & - & - \\
NA & - & - & - & - & - \\
Penicillin G sensitivity & 58 & 61 & 64 & 60 & 55 \\
(Zone diameter, mm) & & & & & \\
\hline
\end{tabular}

+: positive or present, $(+)$ : weakly positive or poor, - : negative or absent

Table 3. Biochemical and genomic characteristics of Korean isolates and $F$. branchiophilum reference strains

\begin{tabular}{|c|c|c|c|c|c|}
\hline Characteristic & CB1 & $\mathrm{CB} 2$ & $\mathrm{CB} 3$ & ATCC $35035^{\mathrm{T}}$ & ATCC35036 \\
\hline \multicolumn{6}{|l|}{ Production of } \\
\hline Cytochrome-c oxidase & + & + & + & + & + \\
\hline Catalase & + & + & + & + & + \\
\hline Hydrogen sulfide & - & - & - & - & - \\
\hline Indole & - & - & - & - & - \\
\hline Flexirubinn & - & - & - & - & - \\
\hline \multicolumn{6}{|l|}{ Degradation of } \\
\hline Gelatin & + & + & + & + & + \\
\hline Starch & + & + & + & + & + \\
\hline Casein & + & + & + & + & + \\
\hline Esculin & - & - & - & - & - \\
\hline Cellulose degradation & - & - & - & - & - \\
\hline Fermentation in & - & - & - & - & - \\
\hline \multicolumn{6}{|l|}{ O-F glucose medium } \\
\hline Nitrate reduction & - & - & - & - & - \\
\hline $\mathrm{Mol} \% \mathrm{G}+\mathrm{C}$ & 30 & 30 & 30 & 31 & 30 \\
\hline
\end{tabular}

+: positive or present, (+): weakly positive or poor, -: negative or absent

antigenic similarity with ATCC $35035^{\mathrm{T}}$ and ATCC 35036.

Immunodiffusion test: The Korean BGD isolates and the BGD reference strains (ATCC $35035^{\mathrm{T}}$ and ATCC 35036) shared many lines of precipitation in double immunodiffusion gels in both tests using formalin-killed antigens and heat-killed antigens.

\section{Discussion}

The results obtained indicate that the yellowpigmented, filamentous, gram-negative bacteria isolated from BGD outbreaks of rainbow trout in Korea are strains of Flavobacterium branchiophilum. Korean isolates share morphological, physiological, biochemical, antigenic, and genomic similarities with the reference 
Table 4. Carbohydrate reactions of Korean isolates and F. branchiophilum reference strains

\begin{tabular}{lccccc}
\hline \hline Carbohydrate & CB1 & CB2 & CB3 & ATCC35035 & ATCC35036 \\
\hline Dextrose & ++ & ++ & ++ & ++ & ++ \\
Fructose & ++ & ++ & ++ & ++ & ++ \\
Lactose & $(+)$ & - & - & - & - \\
Sucrose & ++ & ++ & ++ & ++ & ++ \\
Maltose & ++ & ++ & + & ++ & + \\
Trehalose & + & + & ++ & + & + \\
Cellubiose & + & - & ++ & + & $+)$ \\
Arabinose & $(+)$ & - & - & $(+)$ & ++ \\
Xylose & - & - & - & - & - \\
Rhamnose & - & - & - & - & - \\
Raffinose & - & $(+)$ & - & - & - \\
Mannose & - & - & - & - & - \\
Salicin & - & - & + & - & + \\
Galactose & $(+)$ & - & - & - & - \\
\hline
\end{tabular}

Acid production from cabohydrate; ++: strong, +: moderate, $(+)$ : weak, -: none

Table 5. Agglutinin titers of five rabbit anti-F. branchiophilum sera against homologous and heterologous antigens

\begin{tabular}{lccccc}
\hline \hline & \multicolumn{5}{c}{ Agglutinin titers of antisera to } \\
\cline { 2 - 6 } Agglutinogen & CB1 & CB2 & CB3 & ATCC35035 & ATCC35036 \\
\hline \multicolumn{5}{c}{ Formalin-killed cells } \\
CB1 & 1024 & 512 & 512 & 512 & 1024 \\
CB2 & 512 & 1024 & 512 & 512 & 256 \\
CB3 & 512 & 512 & 1024 & 256 & 512 \\
ATCC35035 & 1024 & 512 & 1024 & 4096 & 128 \\
ATCC35036 & 256 & 256 & 512 & 256 & 1024 \\
& & Heat-killed cells (121 ${ }^{\circ}$ C for 30 min) & \\
CB1 & 64 & 32 & 64 & 32 & 32 \\
CB2 & 32 & 128 & 32 & 64 & 32 \\
CB3 & 64 & 32 & 64 & 32 & 32 \\
ATCC35035 & 64 & 32 & 32 & 128 & 64 \\
ATCC35036 & 64 & 64 & 128 & 64 & 256 \\
\hline
\end{tabular}

strains of $F$. branchiophilum isolated from salmonid fish in Japan (ATCC 35035) and Oregon (ATCC 35036). Further studies of DNA homology between the Korean isolates and reference strains would help establish their genetic relationship.

Electron microscopic studies of Korean isolates of $F$. branchiophilum demonstrated large numbers of thin, fimbria-like structures present on the bacterial surface (Fig. 1). Similar structures were seen on both ATCC 35035 ${ }^{\mathrm{T}}$ and ATCC 35036; these structures have been purified and characterized from ATCC $35035^{\mathrm{T}}$ and appear to be antigenically related among strains of $F$. branchiophilum (Heo et al., 1990).

The antigenic charateristics of Korean BGD isolates were examined. The BGD isolates shared many lines of precipitation in double immunodiffusion gels and high agglutinin titer with the two reference strains. It was reported that Japanese strains and Oregon strains were serologically distinct although they possessed common antigens based on a cross absorption test (Wakabayashi 
et al., 1980; Huh and Wakabayashi, 1989). It can not be concluded by the present results to which type, Japanese or Oregon, the Korean isolates are serologically related.

BGD has been known to occur in fry of rainbow trout and has caused a great economic loss in Korea but etiological agent was not isolated and identified before. This is the first case that the Korean isolates from BGD outbreaks were confirmed to be $F$. branchiophilum.

The disease occurs from February to July in case of ground water and from May to June in case of natural water when water temperatures are about $18^{\circ} \mathrm{C}$ in Korea. Our current recovery rate of $F$. branchiophilum from Korean BGD of rainbow trout still remains poor. The reason for this poor recovery is unknown, but it may be that this bacterium has particular growth requirements that are not met with cytophaga agar. The development of a selective or enrichment medium for isolation of $F$. branchiopilum would improve our understanding of the ecology of this mucosal pathogen.

\section{References}

Anacker, R. L. and E. J. Ordal (1959): Studies on the myxobacterium Chondrococcus columnaris. I. Serological typing. J. Bacteriol., 78, 25-32.

Anderson, J. I. W. and D. A. Conroy (1969): The pathogenic myxobacteria with special reference to fish diseases. $J$. Appl. Bact., 32, 30-39.

Bullock, G. L. (1990): Bacterial gill disease of freshwater fishes. U.S. Fish and Wildlife Service Fish Disease Leaflet, 19.

Daoust, P. Y. and H. W. Ferguson (1983): Gill diseases of cultured salmonids in Ontario. Can. J. Com. Med., 47, 358 362.

Farkas, J. (1985): Filamentous Flavobacterium sp. isolated from fish with gill diseases in cold water. Aquaculture, 44, 110.
Heo, G. J., H. Wakabayashi, and S. Watabe (1990): Purification and characterization of pili from Flavobacterium branchiophila. Fish Pathol., 25, 21-27.

Holmes, B., R. J. Owen and T. H. McMeekin (1984): Genus Flavobacterium. In "Bergey's manual of systematic bacteriology, volume 1" (ed. by N. R. Krieg and J. G. Holt). Williams and Wilkins, Baltimore, Maryland, pp. 353-361.

Huh, G. J. and H. Wakabayashi (1989): Serological characterisitic of Flavobacterium branchiophila isolated from gill diseases of freshwater freshwater fishes in Japan, USA, and Hungary. J. Aquat. Antim. Health, 1, 142-147.

Jin, T. and K. Komagata (1984): Determination of DNA base composition by reversed-phase high-performance liquid chromatography. FEMS Microbiol. Lett., 25, 125-128.

MacFaddin, J. F. (1980): Biochemical tests for identification of medical bacteria, 2nd edition. Williams and Wilkins, Baltimore, Maryland, 527p.

Mitsuoka, T., Morishita Y. and A. Terada (1969): A simple method (plate-in-bottle method) for the cultivation of fastidious anaerrobes. Jap. J. Microbiol., 13, 383-385.

Ostland, V. E., H. W. Ferguson, J. F. Prescott, R. M. W. Stevenson and I. K. Barker (1990): Bacterial gill disease of salmonids; relationship between severity of gill lesions and bacterial recovery. Dis. Aquat. Org., 9, 5-14.

Perry, L. B. (1973): Gliding motility in some non-spreading flexibacteria. J. Appl. Bacteriol., 36, 227-232.

Rucker, R. R., H. E. Johnson and G. M. Kaydas (1952): An interm report on gill disease. Prog. Fish-Cult., 14, 10-14.

Von Graevenitz, A. (1990): Revised nomenclature of Campylobacter laridis, Enterobacter intermedium, and "Flavobacterium branchiophila." Int. J. Syst. Bacteriol., 40, 211.

Wakabayashi, H., S. Egusa and J. L. Fryer (1980): Charactristics of filamentous bacteria isolated from a gill disease of salmonids. Can. J. Fish Aquat. Sci., 37, 1499-1504.

Wakabayashi, H., G. J. Huh and N. Kimura (1989): Flavobacterium branchiophila sp. nov., a causative agent of bacterial gill disease of freshwater fishes. Int. J. Syst. Bacteriol., 39, 213-216. 